\title{
Heritability of tarsus length in cross-fostered broods of the European starling (Sturnus vulgaris)
}

\author{
HENRIK G. SMITH \\ Department of Ecology, Ecology Building, Lund University, S-223 62 Lund, Sweden
}

\begin{abstract}
A cross-fostering experiment demonstrated that tarsus length of European starlings (Sturnus vulgaris) was heritable. The tarsus length of the foster-parent had no effect. A full-sib resemblance analysis showed that sibs were much more similar in tarsus length than explained by heritability alone. This was partly due to an effect of female mating status on offspring tarsus length. When nestling growth was retarded in secondary females' nests due to reduced male assistance, the increased environmental variation in tarsus length masked the heritability.
\end{abstract}

Keywords: cross-fostering, ecological genetics, heritability, starling, Sturnus vulgaris, tarsus length.

\section{Introduction}

Knowledge about the heritability of morphological traits in the wild is essential for understanding natural selection (e.g. Endler, 1986). Heritability might be estimated as the resemblance between offspring and their parents (Falconer, 1981). However, parent-offspring resemblance might also be due to parents and offspring inhabiting a common environment (Falconer, 1981). Therefore cross-fostering experiments are necessary to determine how much of the resemblance is due to heritable variation (e.g. Boag \& van Noordwijk, 1987). This paper reports a cross-fostering experiment on European starlings (Sturnus vulgaris) to determine the heritability of tarsus length in that species.

In birds, morphological traits might be affected by conditions during growth (e.g. Boag, 1987; Dahlgren, 1987; Richner et al., 1989). Such environmental effects might have several important effects. First, heritability estimates might depend on growth conditions (e.g. van Noordwijk et al., 1988). Secondly, natural selection might affect the environmental and genetical part of the morphological variation differently (e.g. van Noordwijk, 1988; Alatalo et al., 1990). In the facultatively polygynous European starling, the growth conditions of nestlings depend to a large extent on the mating status of their mother, since fathers provide very little food to nestlings of secondary and tertiary females (Pinxten \& Eens, 1990; Smith et al., 1993b). In this paper the effect of growth conditions on the final length of the tarsus and its heritability is investigated.

\section{Materials and methods}

The study was performed in 1991-1992 in the Revinge area $20 \mathrm{~km}$ east of Lund in southern Sweden. The area is dominated by permanent pastures grazed by cattle. Starlings bred in colonies of 15-40 nestboxes or in solitary boxes. For details about the study area and methods see Smith et al. (1993b).

Adult starlings were captured both before breeding and during the incubation and nestling feeding periods. Each bird captured was sexed (Svensson, 1984) and its tarsus length determined to the nearest $0.05 \mathrm{~mm}$ using Vernier calipers. Each bird was equipped with an aluminium ring and a unique combination of three colour rings. Repeatability (Lessells \& Boag, 1987) for tarsus length was 0.82 for 52 birds captured more than once ( 106 captures, most birds captured in both years).

During the egg-laying period, nestboxes were visited daily to determine laying dates and clutch sizes. Eggdumping occurs in this population, but was not considered here since only about 1.5 per cent of nestlings originate from parasite eggs (Smith et al., 1993b). Hatching date was determined by daily nest checks. Nestlings were counted and their tarsus lengths measured 14 days after hatching of the first egg in the clutch. At this time the tarsus length of nestlings has reached 99.9 per cent of adult size (based on measurements of 1281 nestlings and 564 adult starlings; see also Feare, 1984).

Parents were assigned to nests by observing them incubating, feeding nestlings or, for some males, by observing them defending nestboxes and building nests 
just before egg-laying. Male starlings attract 1-3 females (Smith et al., 1993b). For colonies where almost all breeding males were known, we assigned a mating status to females. This was done by assuming that laying date reflects mating date which seems to be true for this population (Smith et al., 1993b). Females were classified as monogamous, primary, secondary or tertiary. Due to small sample sizes, secondary and tertiary females were pooled. If one female abandons her nest, another female might change mating status. In this study, mating status refers to the actual status of females when feeding nestlings.

During 1992, we performed a cross-fostering experiment. The primary purpose of this experiment was to test the adaptive significance of egg-size. Available clutches were therefore categorized in relation to egg-size as having heavy $(\geqslant 7 \mathrm{~g})$ or light eggs $(<7 \mathrm{~g})$. The day after clutch completion, whole clutches with the same number of eggs completed on the same day were swapped. Eggs in one nest were replaced by prewarmed plasticine eggs and transported in an insulated box to a second nest. The eggs in the second nest were then transported back to the first nest. Selection of clutches was random except that they were assigned to one of four categories in relation to egg-size (heavy/ heavy, light/light, heavy/light, light/heavy). Since eggsize does not affect tarsus length in starlings (Smith et al., 1993a) this does not affect the results of this study. When no clutch of the same size completed on the same day was available, the clutch was sham-manipulated, but these clutches are not considered in this paper. In four cases one egg was missing or destroyed and replaced with an equally sized, not incubated egg from another nest. Since nestlings were marked when hatching we could exclude this nestling from calculations for two of the nests. For the two other nests we had to exclude it together with a nest-mate since two eggs hatched simultaneously, leaving three and four nestlings to base calculations on. In total 68 experimental clutches were created, but predation by a pine marten Martes martes lowered the sample size considerably.

The fact that tarsus length is sexually dimorphic (266 males: $34.61 \mathrm{~mm} ; 298$ females: $33.99 \mathrm{~mm}$ ) might complicate estimates of heritability. However, the variance was the same for both sexes $(0.53$ vs. 0.54 , $\left.F_{265,297}=0.98, P>0.1\right)$. Assortative mating may affect heritability estimates obtained by single parent-offspring regressions and full-sib resemblance analyses (Falconer, 1981). Males and females did not mate assortatively with respect to tarsus length in 1991 $(r=-0.11, N=108, P=0.24)$ but did so in 1992 $(r=-0.19, N=121, P=0.008)$. For two reasons I do not adjust for this effect. First, the degree of negative assortative mating was small and only significant in one year. Secondly, assortative mating did not affect the cross-fostering experiment $(r=-0.19, \quad N=35$, $P=0.27)$. Estimates from midparent-offspring regressions are not affected by assortative mating (Falconer, 1981).

Statistical analyses were performed using SYSTAT (Wilkinson, 1990). Since year did not prove to be significant in any analysis, years were pooled. Unplanned comparisons were performed using Tukey's HSD method.

\section{Results}

Among control broods there was a significant resemblance between the tarsus length of offspring and that of parents. The heritability estimates were the same when estimated with offspring-midparent regression $\left(h^{2}=0.44, r=0.33, N=121, P<0.001\right)$ as when using offspring-mother regression $\left(h^{2}=0.44, \quad r=0.28\right.$, $N=136, P=0.001)$. It was lower and not significant when using offspring-father regression $\left(h^{2}=0.24\right.$, $r=0.13, N=0.136, P=0.12$ ).

A full-sib resemblance analysis (Falconer, 1981) of 172 broods demonstrated a between-brood component of total variance for nestling tarsus length of 0.44 . This sets an upper limit of heritability to 0.88 . That this estimate is much higher than the results of the parent-offspring regressions above means that there is a large impact of the common nest-environment on sibling resemblance.

The cross-fostering experiment showed no resemblance between the offspring's tarsus length and that of the foster parents (Table 1, Fig. 1). There was a significant resemblance between the tarsus length of the true parents and that of the offspring, demonstrated by significant offspring-midparent and offspring-father regressions and a nearly significant offspring-mother regression (Table 1, Fig. 1).

Tarsus length is also affected by rearing conditions since nestlings in secondary females' broods showed shorter tarsi $\left(F_{2,122}=7.96, P=0.001\right)$. This was not due to secondary females having smaller tarsi, since the result also held true when analysing the effect of female mating status on the difference between the offspring's tarsus lengths and that of the midparent $\left(F_{2,107}=7.00\right.$, $P=0.001$; Fig. 2). Offspring of secondary females showed shorter tarsi relative to parents than both those of monogamous females $(P=0.001$, Tukey HSD $)$ and primary females $(P=0.022)$ whereas those of monogamous and primary females did not differ $(P=0.82)$.

This environmental component of tarsus length variation had an effect on the heritability estimates for control broods. For monogamous and primary females' 
Table 1 Heritability estimates $\left(h^{2}\right)$ of tarsus length from regression of offspring on midparent, mother and father in cross-fostered starling broods

\begin{tabular}{|c|c|c|c|c|c|c|c|c|c|c|}
\hline & \multicolumn{5}{|c|}{ Foster parent } & \multicolumn{5}{|c|}{ True parent } \\
\hline & $h^{2}$ & S.E. & $r$ & $N$ & $P$ & $h^{2}$ & S.E. & $r$ & $N$ & $P$ \\
\hline Midparent & 0.09 & 0.25 & 0.06 & 35 & 0.72 & 0.49 & 0.18 & 0.47 & 27 & 0.01 \\
\hline Mother & 0.44 & 0.34 & 0.21 & 38 & 0.21 & 0.50 & 0.28 & 0.33 & 29 & 0.08 \\
\hline Father & -0.28 & 0.24 & -0.17 & 46 & 0.25 & 0.76 & 0.23 & 0.47 & 41 & 0.002 \\
\hline
\end{tabular}
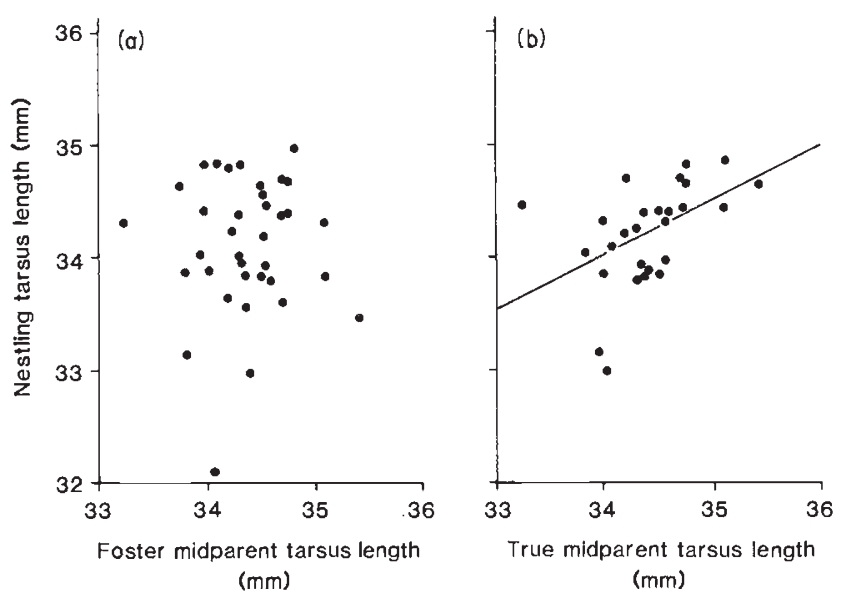

Fig. 1 Regression of offspring tarsus length on (a) foster midparent and (b) true midparent tarsus length in a crossfostering experiment. Line fitted with linear regression.

offspring there was a significant heritability $\left(h^{2}=0.52\right.$, $r=0.44, N=94, P<0.001$; Fig. 3 ), whereas for secondary females' offspring there was no significant heritability $\left(h^{2}=0.33, r=0.16, N=16, P=0.56\right.$; Fig. 3$)$.

The nests included in the cross-fostering study were a random sample of females with different mating status and should thus provide an unbiased estimate of the heritability for tarsus length in this starling population.

\section{Discussion}

This study demonstrated a significant heritability for tarsus length in the European starling. Estimates from parent-offspring regression in control broods were corroborated by a cross-fostering experiment. Also, other cross-fostering studies on birds have demonstrated similar degrees of heritability of tarsus length (song sparrow Melospiza melodia, Smith \& Dhondt, 1980; blue tit Parus caeruleus, Dhondt, 1982; pied flycatcher Ficedula hypoleuca, Alatalo \& Lundberg, 1986; tree swallow Tachycineta bicolor, Wiggins, 1989). Hence, it seems well established that body size of birds has a heritable component.

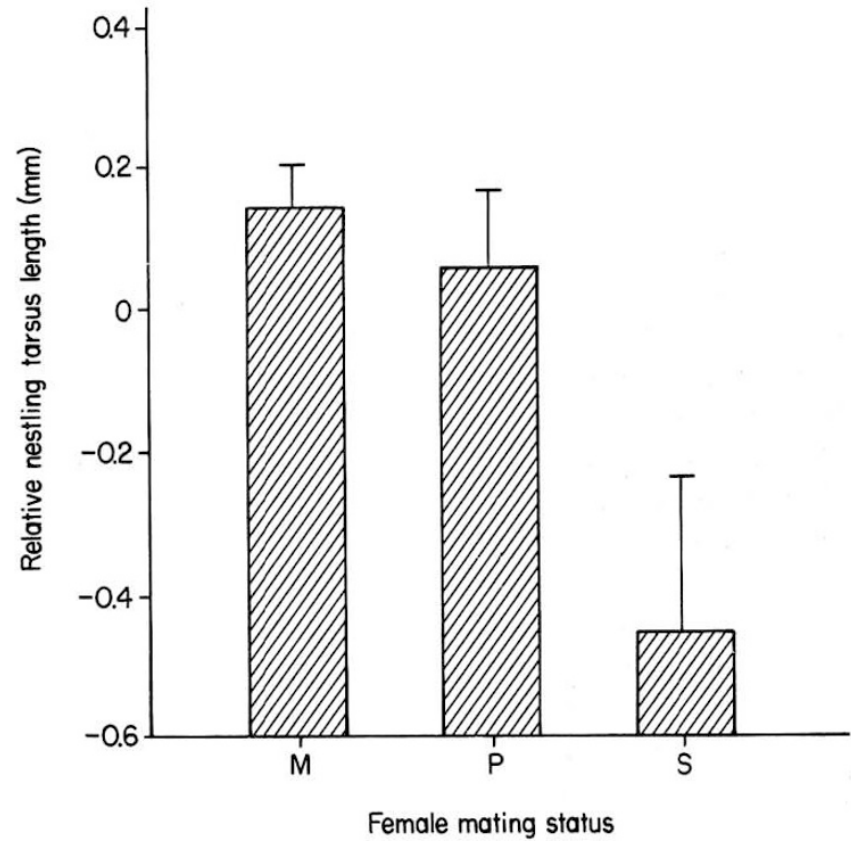

Fig. 2 The deviation of offspring mean tarsus length from the midparent value for offspring in monogamous $(\mathbf{M})$, primary (P) and secondary and tertiary nests (S). Standard error indicated.

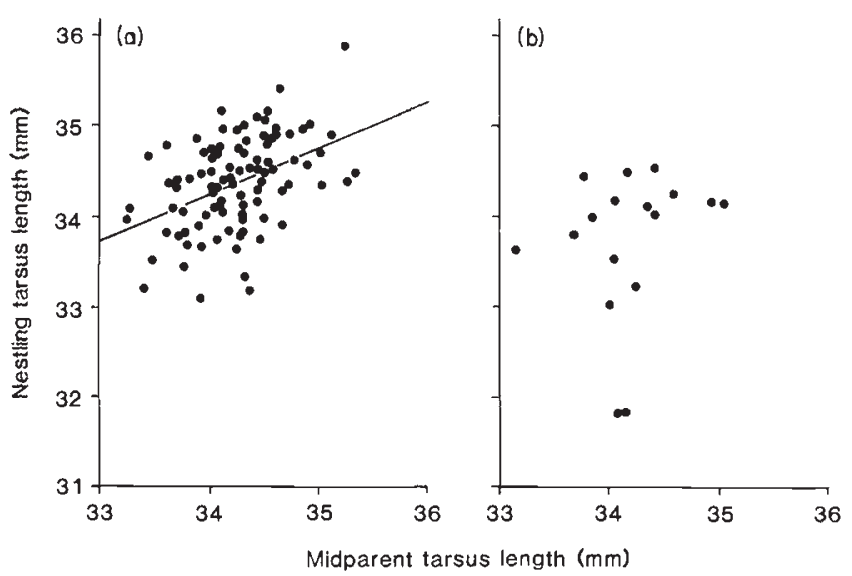

Fig. 3 Regression of offspring tarsus length on midparent tarsus length for control broods. (a) Monogamous and primary nests, (b) secondary and tertiary nests. Line fitted with linear regression. 
However, body size was also affected by growth conditions. Nestlings in secondary females' nests had shorter tarsi so that tarsus lengths were smaller that the midparent tarsus lengths. This is probably due to the lower feeding frequency in secondary nests due to less male assistance (Smith et al., 1993b). Similar environmental effects on body size have also been demonstrated in other studies. For example, young born late in the season (Alatalo \& Lundberg, 1986) or in enlarged broods (Gustafsson, 1985; Lindén, 1988; Alatalo \& Lundberg, 1989) might develop shorter tarsi. As in the present study, Alatalo \& Lundberg (1986) demonstrated an effect of female mating status in pied flycatchers which they attributed to a smaller investment by males in secondary nests.

Alatalo et al. (1990) demonstrated for a population of pied flycatchers that directional selection acted only on the environmental part of the variation in tarsus length with the effect that selection on tarsus length did not produce any evolutionary response (see also van Noordwijk, 1988; Price et al., 1988). A similar effect on starlings is plausible if nestlings from secondary females' nests show lower recruitment rates. Already in the nest, the offspring of secondary females survive less well (Smith et al., 1993b).

We found two factors that affected our estimates of heritability. First, the heritability estimate was only significant for monogamous and primary females, not for secondary and tertiary females. A similar result was found by van Noordwijk et al. (1988), who demonstrated that the resemblance between great tit Parus major offspring and parents was dependent on good rearing conditions. The probable reason for this is that when feeding conditions are poor, the environmental variation is increased and masks the heritable variation.

Secondly, among control broods heritability was lower for the regression of offspring on the father than on the mother. It has been suggested that the difference in apparent heritability when using mother-offspring and father-offspring regressions is due to the lower relatedness between the putative father and the offspring than between the putative mother and the offspring (Alatalo et al., 1984; Parkin \& Wetton, 1991; but see Lifjeld \& Slagsvold, 1989). However, for monogamous and primary starlings the frequency of extra-pair paternity is only 6.5 per cent as estimated by DNA-fingerprinting ( $\mathrm{H}$. H. Smith, unpublished data). Furthermore, the cross-fostering experiment did not corroborate this result from the control nests.

\section{Acknowledgements}

I thank T. Ohlsson, K. Fontell, M. Green, U. Ottosson, M. Sandell and M. Sawander for help with field work.
H. Källander made useful comments on the manuscript. I thank the Swedish Natural Science Research Council for an operating grant to H.G.S. making this study possible.

\section{References}

ALATAlo, R. V. AND LUNDBerg, A. 1986. Heritability and selection on tarsus length in the pied flycatcher (Ficedula hypoleuca). Evolution, 40, 574-583.

Alatalo, R. V. AND LundBerG, A. 1989. Clutch size of the pied flycatcher Ficedula hypoleuca - an experiment. Ornis Fennica, 66, 15-23.

ALATALO, R. V., GUSTAFSSON, L. AND LUNDBERG, A. 1984. High frequency of cuckoldry in pied and collared flycatchers. Oikos, 42, 41-47.

alatalo, R. V., Gustafsson, L. AND Lundberg, A. 1990. Phenotypic selection on heritable size traits: environmental variance and genetic response. Am. Nat., 135, 464-471.

BOAG, P. T. 1987. Effects of nestling diet on growth and adult size of zebra finches (Poephila guttata). Auk, 104, 155-166.

BOAG, P. T. AND VAN NOORDWIJK, A. J. 1987. Quantitative genetics. In: Cooke, F. and Buckley, P. A. (eds) Avian Genetics, Academic Press, London, pp. 45-78.

DAHLGREN, J. 1987. Partridge activity, growth rate and survival: dependence on insect abundance. Unpublished $\mathrm{PhD}$ thesis, Lund University, Sweden.

DHONDT, A. A. 1982. Heritability of blue tit tarsus length from normal and cross-fostered broods. Evolution, 36, 418-419.

ENDler, J. A. 1986. Natural Selection in the Wild. Princeton University Press, Princeton.

FAlCONER, D. S. 1981. Introduction to Quantitative Genetics, 2nd ed. Longman, London.

FEARE, C. 1984. The Starling. Oxford University Press, Oxford.

GUSTAFSSON, L. 1985. Fitness factors in the collared flycatcher Ficedula albicollis Temm. Unpublished PhD thesis, Uppsala University, Sweden.

LESSELLS, C. M. AND BOAG, P. T. 1987. Unrepeatable repeatabilities: a common mistake. Auk, 104, 16-21.

LIFJELD, J. T. AND SLAGSVOLD, T. 1989. How frequent is cuckoldry in pied flycatchers? - Problems with the use of heritability estimates of tarsus length. Oikos, 54, 205-210.

LINDÉN, M. 1988. Reproductive trade-off between first and second clutches in the great tit Parus major: an experimental study. Oikos, 57, 285-290.

PARKIN, D. T. AND WETTON, J. H. 1991. The heritability of tarsus length in house sparrow Passer domesticus. Ibis, 133 (suppl. 1), 134.

PINXTEN, R. AND EENS, M. 1990. Polygyny in the European starling: effects on female reproductive success. Anim. Behav., 40, 1035-1047.

PRICE, T. D., KIRCKPATRICK, M. AND ARNOLD, S. J. 1988. Directional selection and the evolution of breeding date in birds. Science, 240, 798-799. 
RICHNER, H., SCHNEITER, P. AND STIRNIMANN, H. 1989. Life-history consequences of growth rate depression: an experimental study on carrion crows (Corvus corone corone L.). Func. Ecol., 3, 617-624.

SMITH, J. N. M. AND DHONDT, A. A. 1980. Experimental confirmation of heritable morphological variation in a natural population of song sparrows. Evolution, 34, 1155-1158.

SMITH, H. G., OTTOSSON, U. AND OHLSSON, T. 1993a. Interclutch variation in egg size among starlings (Sturnus vulgaris) reflects female quality. Ornis Scand., in press.

SMITH, H. G., OTTOSSON, U. AND SANDELL, M. 1993b. Female competition among polygynously mated female starlings. Rehav. Ecol., in press.

SVENSSON, L. 1984. Identification Guide to European Passerines, 2nd ed. Svensson, Stockholm.
VAN NOORDWIJK, J. 1988. Two-stage selection in which the first stage only reduces the environmental variation in body size in the great tit. In: Ouellet, H. (ed.) Acta XIX Congressus Internationalis Orhithologici, Vol. II, University of Ottawa Press, Ottawa, pp. 1408-1415.

VAN NOORDWIJK, A. J., VAN BALEN, J. H. AND SCHARLOO, W. 1988. Heritability of body size in a natural population of the great tit (Parus major) and its relation to age and environmental conditions during growth. Genet. Res. Camb., 51, 1.49-162.

WIGGINS, D. A. 1989. Heritability of body size in cross-fostered tree swallow broods. Evolution, 43, 1808-1811.

wILKINSON, L. 1990. SYSTAT: The System for Statistics. SYSTAT Inc., Evanston, IL. 